\title{
ANALISIS PENGARUH SUASANA TOKO, VARIASI MERCHANDISE, DAN KUALITAS PELAYANAN TERHADAP KEPUTUSAN PEMBELIAN AKSESORIS GADGET: STUDI KASUS GERAI WELLCOMMSHOP MAL CITRALAND
}

\author{
Tinjung Desy Nursanti; Herlina \\ Jurusan Manajemen, Fakultas Ekonomi dan Komunikasi, BINUS University \\ Jln. K.H. Syahdan No. 9, Palmerah, Jakarta Barat 11480 \\ tinjungdesy@yahoo.com
}

\begin{abstract}
The growing technological applications encourage people to use gadgets as the easiest way to connect their daily lives. The demand for gadgets creates new kind of business opportunities. Many companies can produce supporting product such gadget accessories. One company that engaged in the provision of gadget accessories is Wellcomshop. The company is aggressively increasing sales of gadget accessories. Therefore, the company wants to evaluate the variables that influence purchasing decisions of gadget accessories. The purpose of this study is to determine whether there is influence between variables store atmosphere, merchandise varieties, and quality of service in determining purchasing decisions in Wellcomm Accessories Gadget Shop Mall Citraland. This study is an associative research and using a simple method of correlation and multiple regressions. The population in this study is the consumer Wellcommshop Citraland Mall, while the samples are 90 respondents. The results show that the variation of merchandise (x2) and quality of service (x3) has a significant influence on purchase decisions. While, the atmosphere of the store $(x 1)$ does not significantly influence purchasing decisions.
\end{abstract}

Keywords: gadget accessories, variation of merchandise, store atmospehere, quality of service

\begin{abstract}
ABSTRAK
Aplikasi teknologi yang sedang berkembang mendorong orang untuk menggunakan gadget sebagai jalan termudah untuk menghubungkan kehidupan sehari-hari mereka. Permintaan akan gadget menciptakan peluang bisnis baru. Banyak perusahaan dapat menghasilkan produk pendukung seperti aksesori gadget. Salah satu perusahaan yang bergerak di bidang penyedia aksesori gadget adalah Wellcomshop. Perusahaan ini secara agresif meningkatkan penjualan aksesori gadget. Oleh karena itu, perusahaan ini ingin mengevaluasi variabel yang memengaruhi putusan pembelian aksesori gadget. Tujuan penelitian ini adalah untuk menentukan adanya pengaruh antara variabel suasana toko, ragam barang dagangan, dan kualitas layanan dalam menentukan putusan pembelian di Wellcomm Accessories Gadget Shop Mall Citraland. Penelitian ini merupakan penelitian asosiatif dan menggunakan metode regresi korelasi dan berganda sederhana. Persebaran dalam penelitian ini adalah konsumen Wellcommshop Citraland Mall, sementara sampel terdiri dari 90 responden. Hasil penelitian menunjukkan ragam dagangan (x2) dan kualitas layanan (x3) memiliki pengaruh yang signifikan terhadap keputusan pembelian. Akan tetapi, suasana toko (x1) tidak secara signifikan memengaruhi keputusan pembelian.
\end{abstract}

Kata kunci: aksesori gadget, variasi merchandise, suasana toko, kualitas layanan 


\section{PENDAHULUAN}

Kemajuan teknologi pada masa ini dirasakan semakin berkembang. Hal ini dapat dilihat salah satunya dari banyaknya masyarakat yang menggunakan berbagai aplikasi teknologi dalam mempermudah segala urusannya. Adapun salah satu bentuk aplikasi teknologi yang begitu diminati masyarakat saat ini adalah gadget. Gadget selalu didesain secara lebih pintar dibandingkan dengan teknologi normal pada masa penemuannya. Saat ini gadget kebanyakan digunakan sebagai kebutuhan untuk pemenuhan gaya hidup yang cenderung mengalami perubahan dari waktu ke waktu. Permintaan atas gadget menciptakan peluang bisnis baru yang dapat dikembangkan sejumlah perusahaan untuk mendukung kelengkapan gadget tersebut, misalnya melengkapinya dengan aksesoris gadget. Oleh karena itu, dapat dilihat bahwa terjadi peningkatan bisnis pembuatan aksesoris gadget yang saat ini dapat ditemukan di beberapa pusat perbelanjaan terkemuka di Jakarta.

PT Wellcomm Ritelindo Pratama sejak tahun 2005 sebagai anak perusahaan dari PT Wellcomm Indo Pratama, PT Wellcomm Ritelindo Pratma merintis jaringan ritel khusus aksesoris gadget. Sebuah ritel yang belum ada sebelumnya dan digarap dengan manajemen ritel modern. Konsep yang dijalankan adalah ritel khusus aksesoris gadget di pasar modern. Jaringan toko khusus aksesoris ini sudah eksis sejak tahun 2006. Tersebar di berbagai mal di kota-kota besar, Indonesia. Nama dari jaringan ritel ini adalah Wellcommshop. Kini sudah kurang lebih 100 gerai yang dimiliki oleh PT Wellcomm Ritelindo Pratama yang sudah tersebar di wilayah Jabotabek dan di luar Jakarta. Jaringan ini hanya fokus menggarap aksesoris gadget, dan tidak menjual produk utama gadget, seperti smartphone, handphone, laptop, dan komputer (Adiwaluyo, Februari 2010).

Wellcommshop berusaha melakukan penetrasi pasarnya secara meluas ke sejumlah pengguna gadget yang dirasakan masih terbuka lebar peluangnya dengan cara membuka sejumlah gerai-gerainya di sejumlah mal besar di Jakarta salah satunya Mal Citraland. Tujuanyang ingin dicapai atas pembukaan sejumlah gerai tersebut adalah memperluas pangsa pasar melalui ritel modern maupun sebagai distributor untuk menarik konsumen sebanyak-banyaknyasertaterus meningkatkan penjualannya dengan tujuan mendapatkan laba.Lokasi Mal Citraland yang terletak dibilangan Jakarta Barat ini termasuk mal yang paling ramai dikunjungi, mulai dari siswa SMU hingga para eksekutif muda. Hal ini juga dikarenakan lokasi mal yang sangat strategis, berada diantara dua unversitas yang terkemuka di Jakarta dan juga berdekatan dengan terminal bus dalam kota Grogol sehingga membuat lokasi ini diminati banyak peritel untuk memasarkan dagangannya. Salah satu cara yang dapat dilakukan perusahaan agar dapat menarik konsumen untuk melakukan pembelian adalah dengan menghadirkan suasana toko yang menyenangkan dan menarikdi dalamnya. Masyarakat saat ini tidak hanya sekedar membeli barang-barang yang diperlukan saja, akan tetapi kegiatan belanja saat ini lebih cenderung dianggap sebagai kegiatan dalam mengisi waktu luang, rekreasi, hiburan, atau sebagai pelepas lelah saja. Untuk itulah setiap pelaku usaha diharapkan mampu memahami suasana apa yang dibutuhkan konsumen saat berbelanja untuk memenuhi kebutuhan dan keinginan mereka. Suasana atau atmosfer dalam toko yang menyenangkan akan mempengaruhi perilaku konsumen dalam mengunjungi sebuah toko, hal ini akan mempengaruhi konsumen dalam mengambil keputusan apakah ia mau membeli produk atau tidak.

Peritel harus mampu mengantisipasi perubahan-perubahan yang terjadi di dalam pasar dan tanggap mengadaptasikannya ke dalam bisnis mereka sehingga sesuai dengan gaya hidup. Bentuk dan konsep-konsep baru serta ide-ide kreatif mengenai bagaimana berbelanja dengan lebih nyaman dan menyenangkan dengan lokasi mudah dicapai dan memiliki point of interest bagi konsumen patut dipertimbangkan. Bentuk desain yang unik akan membantu para pemilik untuk dapat secara kreatif menciptakan suasana toko yang menarik bagi para pengunjung. Sebuah pengelolaan yang mengintegrasikan desain interior, pilihan barang, dan konsep toko. Dengan desain interior toko yang tepat, diharapkan pengunjung dapat tertarik untuk menentukan pilihan toko. Desain ini tidak terlepas 
dari kondisi sosial ekonomi dan gaya hidup masyarakat. Adanya evolusi dari bentuk-bentuk pusat perbelanjaan itu sendiri akan mendorong bentuk-bentuk interior masing-masing toko sehingga menjadi lebih kreatif. Selain suasana toko, variasimerchandisedalam gerai dapat memunculkan minat konsumen untuk melakukan pembelian. Variasimerchandise didalam gerai bertujuan agar para konsumen dimanjakan dengan banyaknya pilihan. Persaingan bisnis yang semakin komplek juga ikut menimbulkan keanekaragaman produk yang ditawarkan. Melalui gerai, konsumen dapat membeli dan menikmati aksesoris gadget untuk kebutuhan pribadi sebagai pelengkap, pelindung maupun penghias gadget yang dimiliki.

Dalam bisnis ritel modern, kualitas pelayanan sangat menentukan dan mendukung keputusan pembelian konsumen, dimana kualitas pelayanan kepada konsumen haruslah memuaskan. Adapun pelayanan tambahan berupa proses untuk mendapatkan barang yang mereka beli, disertai beberapa layanan yang dimulai dengan mendapatkan barang yang diinginkan hingga layanan kasir pada proses pembayaran. Hal ini penting mengingat apabila konsumen puas, diharapkan akan memberikan gambaran yang baik terhadap perusahaan dan konsumen akan melakukan pembelian ulang serta merekomendasikannya kepada orang lain. Sebaliknya bila pelayanan mengecewakan maka kesan yang tercipta akan buruk jadinya.

Indentifikasi masalah dan tujuan penelitian adalah: (1) untuk mengetahui bagaimana pengaruh suasana toko terhadap keputusan pembelian di Gerai Wellcommshop Mal Citraland; (2) untuk mengetahui bagaimana pengaruh variasi merchandise terhadap keputusan pembelian di Gerai Wellcommshop Mal Citraland; (3) untuk mengetahui bagaimana pengaruh kualitas pelayanan terhadap keputusan pembelian di Gerai Wellcommshop Mal Citraland; dan (4) untuk mengetahui bagaimana pengaruh suasana toko, variasi merchandise, dan kualitas pelayanan terhadap keputusan pembelian di Gerai Wellcommshop Mal Citraland.

\section{Pengertian Ritel}

Sopiah dan Syihabudhin (2008) menjelaskan mengenai retailing atau eceran yang artinya, kegiatan menjual barang dan jasa kepada konsumen akhir. Perdagangan eceran adalah mata rantai terakhir dalam penyaluran barang dari produsen sampai kepada konsumen.Whidya (2006) menyebutkan bahwa ritel merupakan perangkat dari aktivitas-aktivitas bisnis yang melakukan penambahan nilai terhadap produk-produk dan layanan penjualan kepada para konsumen untuk penggunaan atau konsumsi perorangan maupun keluarga. Sedangkan Hendri (2005) menjelaskan konsep peritel atau pengecer adalah pengusaha yang menjual barang dan jasa secara eceran kepada masyarakat sebagai konsumen.

Gerai dalam segala bentuknya berfungsi sebagai tempat pembelian barang dan jasa dan merupakan terjemahan dari oultet, yaitu dalam arti konsumen datang ke gerai untuk melakukan transaksi berbelanja dan membawa pulang barang atau menikmati jasa. Gerai-gerai dari peritel kecil terdiri atas dua macam, yaitu gerai modern dan gerai tradisional. Gerai modern adalah penataan barang menurut keperluan yang sama dikelompokan di bagian yang sama dapat dilihat dan diambil langsung oleh pembeli, penggunaan alat pendingin udara, dan adanya pramuniaga profesional. Gadget adalah suatu istilah yang berasal dari bahasa inggris untuk merujuk pada suatu peranti atau instrumen yang memiliki tujuan dan fungsi praktis spesifik yang berguna yang umumnya diberikan terhadap sesuatu yang baru. Gadget dirancang secara berbeda dan lebih canggih dibandingkan teknologi normal yang ada pada saat penciptaannya.

\section{Suasana Toko}

Menurut Gilbert (2003), suasana toko merupakan kombinasi dari pesan sebagai fisik yang telah direncanakan. Atmosfer toko dapat digambarkan sebagai perubahan terhadap perancangan 
lingkungan pembelian yang menghasilkan efek emosional khusus yang dapat menyebabkan konsumen melakukan tindakan pembelian.Menurut Kotler (2003) suasana toko setiap toko mempunyai tata letak fisik yang memudahkan atau menyulitkan untuk berputar-putar di dalamnya. Setiap toko mempunyai penampilan yang berbeda-beda baik itu menarik, megah dan suram.Suasana toko harus membentuk suasana terencana yang sesuai dengan pasar sasarannya dan dapat menarik konsumen untuk membelinya di toko tersebut.Dengan demikian store atmosphere (suasana toko) merupakan persepsi suasana toko sebagai akibat dari pengaruh efek-efek yang diciptakan pengusaha untuk membuat suatu toko agar menarik untuk dikunjungi oleh konsumen, yang tercipta dari gabungan unsur-unsur desain eksterior (interior gerai, visual, jalan masuk, pencahayaan), atmosfer/ambience (aural, olfactory, tactile), layout (tata letak).

\section{Variasi Merchandise}

Menurut Sopiah (2008), merchandising merupakan salah satu bidang yang berperan dalam menentukan keunggulan bersaing dari peritel. Adapun Sujana (2004), menjelaskan pengertian merchandisesebagai suatu rentang bauran produk yang disediakan untuk memenuhi kebutuhan konsumen, merupakan komponen investasi terbesar karenanya bisa disebut sebagai urat nadi bisnis ritel. Ma'ruf (2006) mendeskripsikan merchandisesebagai produk-produk yang dijual peritel atau pengecer dalam gerainya. Merchandise yang akan dijual penting dipilih dengan benar karena merupakan mesin sukses bagi pengecer. Keragaman produk terdiri atas dua hal yaitu banyak variasi kategori produk yang dijual, dan banyaknya item pilihan dalam masing-masing kategori produk.

\section{Kualitas Pelayanan}

Menurut Tjiptono (2005), kualitas pelayanan adalah tingkat keunggulan yang diharapkan dan pengendalian atas tingkat keunggulan tersebut untuk memenuhi keinginan pelanggan. Simamora (2003), mendefinisikan kualitas pelayanan adalah upaya pemenuhan kebutuhan dan keinginan pelanggan serta penyampaiannya untuk mengimbangi harapan pelanggan.Berdasarkan pengertian diatas dapat disimpulkan bahwa kualitas pelayanan adalah kinerja yang mengarah pada mutu yang diharapkan dari yang ditawarkan secara lebih mendalam karena manfaat besar yang dihasilkan dari pelayanan, yang dapat meningkatkan intensitas pembelian dan loyalitas pelanggan.

\section{Keputusan Pembelian}

Menurut Schiffman dan Kanuk (2007, p285), "keputusan pembelian konsumen adalah seleksi terhadap dua pilihan atau lebih. Dengan kata lain, pilihan alternatif harus tersedia bagi seseorang ketika mengambil keputusan” (p. 285). Sedangkan Olson (2002), menjelaskannya sebagai proses pengintegrasian yang mengkombinasikan pengetahuan dan mengevaluasi dua atau lebih perilaku alternatif dan memilih salah satu diantaranya. Hasil dari proses pengintegrasian ini adalah suatu pilihan yang disajikan secara kognitif sebagai keinginan berperilaku.

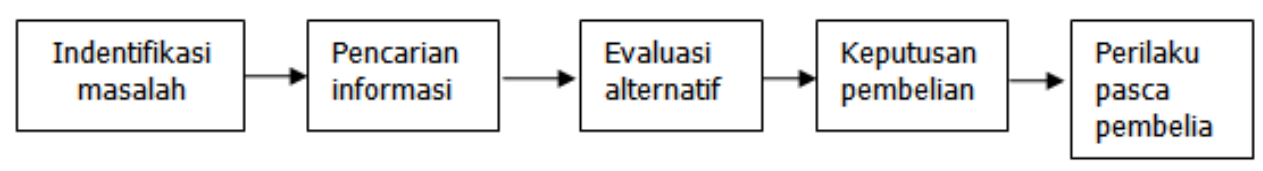

Gambar 1 Tahap pengambilan keputusan pembelian Sumber: Kotler (2005) 


\section{Hipotesis}

Beberapa hipotesis dari penelitian ini adalah:

H0: Tidak ada pengaruh yang signifikan antara suasana toko terhadap keputusan pembelian

H1: Ada pengaruh yang signifikan antara suasana toko terhadap keputusan pembelian

H0: Tidak ada pengaruh yang signifikan antara variasi merhandise terhadap keputusan pembelian.

H1: Ada pengaruh yang signifikan antara variasi merchandise terhadap keputusan pembelian.

H0: Tidak ada pengaruh yang signifikan antara kualitas pelayanan terhadap keputusan pembelian.

H1: Ada pengaruh yang signifikan antara kualitas pelayanan terhadap keputusan pembelian.

H0: Ada pengaruh yang signifikan antara suasana toko, variasi merchandise, dan kualitas pelayanan terhadap keputusan pembelian

H1: Ada pengaruh yang signifikan antara suasana toko, variasi merchandise, dan kualitas pelayanan terhadap keputusan pembelian.

\section{METODE}

\section{Desain Penelitian}

Penelitian ini merupakan penelitian asosiatif dengan mengumpulkan data sampel secara cross sectional dengan one shoot dimana data dikumpulkan hanya pada kurun waktu tertentu saja.Metode penelitian yang digunakan adalah survey, dengan unit analisis yang dituju adalah individu yaitu para konsumen yang membeli aksesoris gadget di Wellcommshop Mal Citraland. Jenis penelitian yang digunakan dalam penelitian ini adalah studi kasus. Studi kasus merupakan penelitian dengan karakteristik masalah yang berkaitan dengan latar belakang dan kondisi saat ini dari objek yang diteliti, serta interaksinya dengan lingkungan (Indriantoro dan Supomo, 2002).

Tabel 1 Desain Penelitian

\begin{tabular}{|c|c|c|c|c|}
\hline \multirow[b]{2}{*}{$\begin{array}{l}\text { Tujuan } \\
\text { Penelitian }\end{array}$} & \multicolumn{4}{|c|}{ Desain Penelitian } \\
\hline & $\begin{array}{c}\text { Jenis } \\
\text { Penelitian }\end{array}$ & $\begin{array}{c}\text { Metode } \\
\text { Penelitian }\end{array}$ & $\begin{array}{c}\text { Unit } \\
\text { Analisis }\end{array}$ & Time Horizon \\
\hline $\mathrm{T}-1$ & Asosiatif & Survey & $\begin{array}{l}\text { Individu-Konsumen Wellommshop Mal } \\
\text { Citraland }\end{array}$ & Cross Sectional \\
\hline $\mathrm{T}-2$ & Asosiatif & Survey & $\begin{array}{l}\text { Individu - Konsumen Wellcommshop } \\
\text { Mal Citraland }\end{array}$ & Cross Sectional \\
\hline $\mathrm{T}-3$ & Asosiatif & Survey & $\begin{array}{l}\text { Individu - Konsumen Wellcommshop } \\
\text { Mal Citraland }\end{array}$ & Cross Sectional \\
\hline $\mathrm{T}-4$ & Asosiatif & Survey & $\begin{array}{l}\text { Individu - Konsumen Wellcommshop } \\
\text { Mal Citraland }\end{array}$ & Cross Sectional \\
\hline
\end{tabular}

Sumber: Penulis, 2010

\section{Operasional Variabel Penelitian}

Dalam penelitian ini digunakan beberapa variabel meliputi: variabel bebas dan terikat. Variabel Independent (Variabel Bebas), terdiri dari: (1) suasana toko (X1): suasana dalam toko berperan penting memikat pembeli, membuat nyaman para konsumen memilih barang belanjaan; (2) variasi merchandise (X2): variasi produk yang di jual peritel atau pengecer dalam gerainya; (3) kualitas pelayanan (X3): kualitas pelayanan adalah penilaian konsumen tentang keandalan dan superioritas pelayanan secara keseluruhan. 
Variabel Dependent (Variabel Terikat), terdiri dari keputusan pembelian(Y): proses pengintegrasian yang mengkombinasikan pengetahuan untuk mengevaluasi dua atau lebih perilaku alternatif dan memilih salah satu di antaranya.

Tabel 2 Definisi operasional variabel penelitian

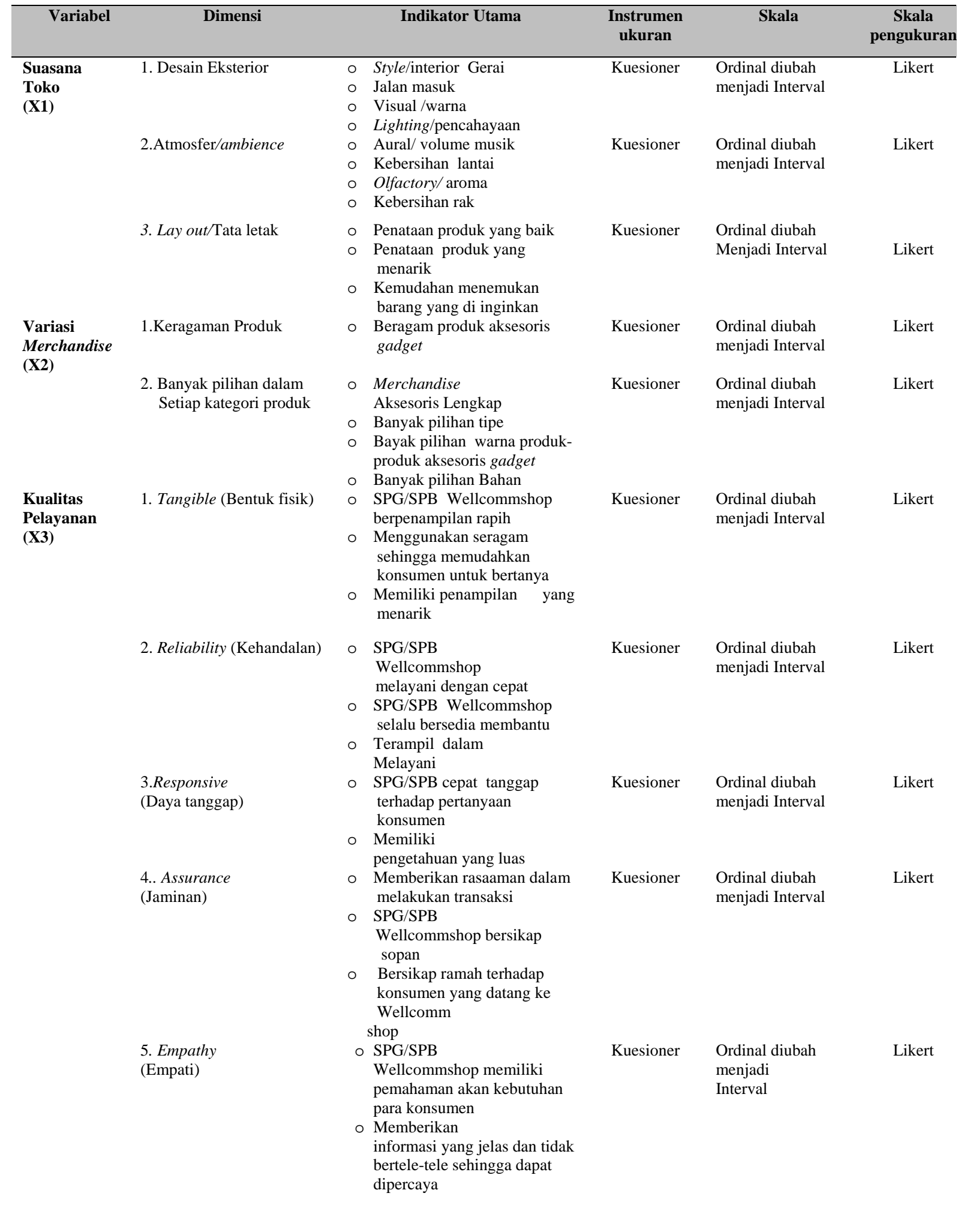




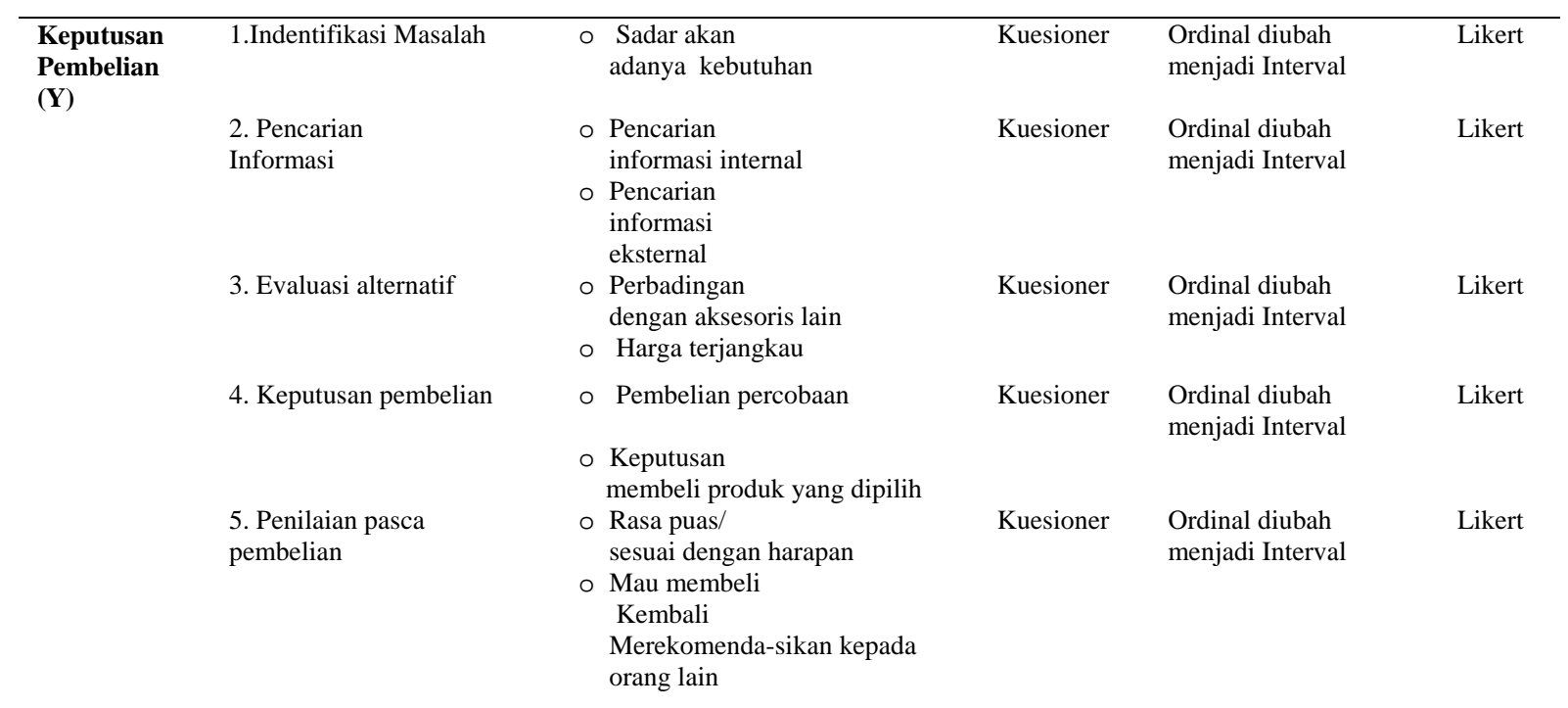

Sumber: Penulis (2010)

\section{Jenis dan Sumber Data Penelitian dan Waktu Penelitian}

Jenis penelitian ini adalah kuantitatif. Digunakan data primer, yang diperoleh dari tanggapan responden, pertanyaan, keterangan dan penilaian konsumen.Di samping itu digunakan juga data sekunder, seperti hasil studi pustaka. Objek dari penelitian ini adalah konsumen Wellcommshop Mal Citraland, dan proses pengumpulan data melalui penyebaran kuesioner mulai dilakukan pada bulan Februari 2010 hingga akhir Mei 2010. Demikian pula wawancara dilakukan terhadap Manajer pemasaran, Manajer HRD, Manajer Desain untuk mengetahui keadaan yang terjadi dalam perusahaan

\section{HASIL DAN PEMBAHASAN}

\section{Profile Responden}

Objek dari penelitian ini adalah para konsumen Wellcommshop Mal Citraland. Informasi mengenai responden ini diperoleh secara langsung melalui kuesioner yang diisi oleh para konsumen. Profile responden ini didapat berdasarkan beberapa informasi seperti jenis kelamin, usia, pekerjaan, dan pengeluaran per bulan. Jumlah responden berdasarkan jenis kelamin ditunjukkan pada Tabel 3.

Tabel 3 Profil responden berdasarkan jenis kelamin

\begin{tabular}{lcc}
\hline \multicolumn{1}{c}{ Jenis kelamin } & Frekuensi & Persentasi \\
\hline Pria & 36 & $40 \%$ \\
Wanita & 54 & $60 \%$ \\
Total & 90 orang & $100 \%$ \\
\hline
\end{tabular}

Sumber: Data primer2010 
Tabel 4 Profil responden berdasarkan usia

\begin{tabular}{lcc}
\hline \multicolumn{1}{c}{ Usia } & Frekuensi & Persentasi \\
\hline$<17$ tahun & 23 & $25,6 \%$ \\
$17-26$ tahun & 37 & $41,11 \%$ \\
$27-36$ tahun & 13 & $14,44 \%$ \\
$37-46$ tahun & 11 & $12,22 \%$ \\
$>46$ tahun & 6 & $6,67 \%$ \\
Total & 90 orang & $100 \%$ \\
\hline
\end{tabular}

Sumber: Data primer 2010

Tabel 5 Profil responden berdasarkan pekerjaan

\begin{tabular}{lcc}
\hline \multicolumn{1}{c}{ Pekerjaan } & Frekuensi & Persentasi \\
\hline Pelajar Sekolah & 23 & $25,55 \%$ \\
Mahasiswa/i & 37 & $41,11 \%$ \\
Karyawan & 10 & $11,11 \%$ \\
Wirausaha & 8 & $8,89 \%$ \\
Lainnya & 12 & $13,33 \%$ \\
Total & 90 orang & $100 \%$
\end{tabular}

Sumber : Data primer 2010

Tabel 6 Profil responden berdasarkan pengeluaran per bulan

\begin{tabular}{ccc}
\hline Pengeluaran & Frekuensi & Persentasi \\
\hline$<$ Rp 500.000 & 13 & $14,44 \%$ \\
Rp 500.000-1.500.000 & 45 & $50 \%$ \\
Rp 1.500.000-2.500.000 & 15 & $16,67 \%$ \\
Rp 2.500.000 - 3.500.000 & 7 & $7,78 \%$ \\
> Rp 3.500.000 & 10 & $11,11 \%$ \\
Total & 90 orang & $100 \%$ \\
\hline
\end{tabular}

Sumber : Data Primer 2010

\section{Uji Validitas}

Uji validitas menggunakan tingkat kepercayaan 95\%. Dimana $\mathrm{df}=\mathrm{n}-2$ dan nilai $\mathrm{n}$ adalah 90 responden. Data yang digunakan adalah data kuesioner nomer 1-90 dengan begitu df yang didapat adalah 88. Setelah mengetahui nilai df, selanjutnya didapat nilai t tabel 1.66 dan nilai $\mathrm{r}$ tabel 0.17 . Untuk validitas, butir pernyataan dimana $r$ hitung $>r$ tabel, maka butir tersebut dianggap valid. Sebaliknya $r$ hitung $<\mathrm{r}$ tabel maka butir tersebut dianggap tidak valid.

\section{Uji Reliabilitas}

Uji reliabilitas bertujuan untuk menunjukkan sejauh mana suatu hasil pengukuran realtif konsisten apabila alat ukur digunakan berulang kali. Karena hasilnya yang konsisten itu, maka alat ukur itu dapat dipercaya (reliable) atau dapat diandalkan (dependable). Reliabilitas dilakukan pada tiap-tiap item kuesioner dengan menggunakan program SPSS 16.0 for windows dengan melihat koefisien nilai cronbach alpha. Kuesioner dikatakan reliabel apabila cronbach alpha $>\mathrm{r}$ tabel dan sebaliknya tidak reliabel apabila cronbach alpha $<\mathrm{r}$ tabel. Nilai Cronbach Alpha adalah positif dan lebih besar dari 0,6 maka semua variabel adalah reliable. 


\section{Uji Normalitas}

Dengan menggunakan bantuan program SPSS 16.0seluruh variabel dalam penelitian ini berdistribusi normal dengan tingkat signifikansi 0.087, 0.302, 0.641, 0.014 untuk masing-masing variabel.

\section{Analisis Deskriptif}

Untuk penilaian responden terhadap suasana toko, diperoleh pandangan nilai terendah (raguragu) yaitu dalam hal pencahayaan dalam Wellcommshop, memiliki suhu dan aroma membuat nyaman, penempatan produk di Wellcommshop untuk memudahkan konsumen mencarinya dan desain interior Wellcommshop masih belum dikategorikan unik dan lucu oleh konsumen.Adapun hasil penilaian responden terhadap variasi pilihan gadget yaitu ada variasi pilihan bahan aksesoris gadget di Wellcommshop, danpilihan tipe aksesoris sesuai dengan type gadget konsumen miliki. Sedangkan hasil penilaian responden terhadap kualitas pelayanan Wellcommshop adalah bahwa SPG/SPB bersikap ramah terhadap konsumen yang datang ke dalam Wellcommshop dan kecepatan SPG/SPB dalam melayani konsumen.Adapun dalam keputusan pembelian, responden mempunyai pandangan bahwa konsumen membeli aksesoris gadget di Wellcommshop karena ingin tahu atau coba-coba. Selain itu ada rasa puas dalam melakukan proses pembelian hingga akhir transaksi di Wellcommshop.

\section{Analisis Pengaruh antara Suasana Toko dengan Keputusan Pembelian aksesoris Gadget}

Tabel 7 Descriptive Statistics

Descriptive Statistics

\begin{tabular}{|l|r|r|r|}
\hline & \multicolumn{1}{|c|}{ Mean } & Std. Deviation & \multicolumn{1}{|c|}{ N } \\
\hline $\mathrm{Y}$ & 3.5084 & .43964 & 90 \\
$\mathrm{x} 1$ & 3.5291 & .44279 & 90 \\
\hline
\end{tabular}

Sumber : Hasil Pengolahan data, 2010

Nilai rata-rata keputusan pembelian konsumen 3,5084 dengan standar deviasi 0,43964. Nilai rata-rata suasana toko 3,5291 dengan standar deviasi 0,44279.

Tabel 8 Korelasi antara Suasana Toko (X1) terhadap Keputusan Pembelian (Y)

Correlations
\begin{tabular}{|lc|r|r|}
\hline \multicolumn{1}{|c|}{} & $\mathrm{y}$ & \multicolumn{1}{c|}{$\mathrm{x} 1$} \\
\hline Pearson Correlation & $\mathrm{Y}$ & 1.000 & .740 \\
& $\mathrm{x} 1$ & .740 & 1.000 \\
\hline Sig. (1-tailed) & $\mathrm{Y}$ &. & .000 \\
& $\mathrm{x} 1$ & .000 & \\
\hline $\mathrm{N}$ & $\mathrm{Y}$ & 90 & 90 \\
& $\mathrm{x} 1$ & 90 & 90 \\
\hline
\end{tabular}

Sumber: Hasil Pengolahan Data SPSS ver 16.0 
Berdasarkan tabel 4.26 diketahui besar korelasi antara suasana tokodengan keputusan pembelian adalah sebesar 0.740 . Artinya, kedua variabel tersebut menunjukkan tingkat hubungan yang kuat dan searah karena angka tersebut positif. Tingkat signifikan antara variabel suasana toko dengan keputusan pembelian sebesar 0.000. Ketentuan menyatakan jika angka probabilitas $<0.05$ maka ada pengaruh yang signifikan antara kedua variabel tersebut.

Tabel 9 Hasil Koefisien Determinasi Suasana Toko (X1)

Model Summary

\begin{tabular}{|c|c|c|c|c|}
\hline Model & $\mathrm{R}$ & R Square & Adjusted R Square & $\begin{array}{c}\text { Std. Error of the } \\
\text { Estimate }\end{array}$ \\
\hline 1 & $.740^{\mathrm{a}}$ & .547 & .542 & .29744 \\
\hline
\end{tabular}

a. Predictors: (Constant), $\mathrm{x} 1$

b. Dependent Variable: y

Sumber: Hasil Pengolahan Data SPSS ver 16.0

Nilai koefisien korelasi antara variabel suasana toko dengan variabel keputusan pembelian adalah 0.740, menunjukkan hubungan yang positif dan kuat antara suasana toko dengan keputusan pembelian. Nilai koefisien determinasi di atas sebesar 0.547 atau $54.7 \%$, yang berarti besarnya pengaruh suasana toko terhadap keputusan pembelian sebesar $54.7 \%$, sedangkan sisanya $45.3 \%$ (100\% - 54.7\%), dipengaruhi oleh variabel lain.

Tabel 10 Anova

ANOVA $^{b}$

\begin{tabular}{|ll|r|r|r|r|r|}
\hline Model & & Sum of Squares & df & Mean Square & F & \multicolumn{1}{c|}{ Sig. } \\
\hline 1 & Regression & 9.417 & 1 & 9.417 & 106.437 & $.000^{\mathrm{a}}$ \\
& Residual & 7.785 & 88 & .088 & & \\
& Total & 17.202 & 89 & & & \\
\hline
\end{tabular}

a. Predictors: (Constant), $\mathrm{x} 1$

b. Dependent Variable: $y$

Sumber: Pengolahan data, 2010

Dari uji ANOVA diatas, didapat F hitung adalah 106.437 dengan tingkat signifikan 0,000< 0.05, oleh karena itu H0 ditolak dan H1 diterima. Artinya, ada hubungan linier antara variabel suasana toko dengan keputusan pembelian, berarti suasana toko memang mempengaruhi keputusan pembelian.

Tabel 11 Koefisien Regresi Sederhana Suasana Toko Terhadap Keputusan Pembelian

Coefficients $^{\text {a }}$

\begin{tabular}{|c|c|c|c|c|c|c|}
\hline \multirow{2}{*}{\multicolumn{2}{|c|}{ Model }} & \multicolumn{2}{|c|}{ Unstandardized Coefficients } & \multirow{2}{*}{$\begin{array}{c}\text { Standardized } \\
\text { Coefficients }\end{array}$} & \multirow[b]{2}{*}{$\mathrm{t}$} & \multirow[b]{2}{*}{ Sig. } \\
\hline & & B & Std. Error & & & \\
\hline \multirow[t]{2}{*}{1} & (Constant) & .916 & .253 & & 3.617 & .000 \\
\hline & $\mathrm{x} 1$ & .735 & .071 & .740 & 10.317 & .000 \\
\hline
\end{tabular}

Sumber : Hasil Pengolahan Data, 2010 
Analisis Output:

Berdasarkan tabel 4.27 menggambarkan persamaan regresi

$\mathrm{Y}=\mathrm{a}+\mathrm{bx}$

$\mathrm{Y}=0.916+0.735 \mathrm{X}$

Di mana: $\mathrm{Y}=$ Keputusan Pembelian

$\mathrm{X}=$ Suasana Toko

Simpulan yang didapat yaitu: (1) nilai B constant sebesar 0.916 menyatakan bahwa jika tidak ada kenaikan nilai dari variabel suasana toko, maka nilai keputusan pembelian tetap 0.916; (2) Nilai B menyatakan bahwa koefisien regresi suasana toko sebesar 0.735 artinya setiap peningkatan suasana tokoakan meningkatkan nilai keputusan pembelian; (3) pada tabel koefisien juga terdapat nilai $t$ hitung. Uji t berguna untuk menguji signifikansi koefisien regresi, yaitu apakah suasana toko berpengaruh terhadap keputusan pembelian secara signifikan atau tidak, yang ternyata terdapat pengaruh yang signifikan antara suasana toko terhadap keputusan pembelian. Ada pengaruh yang signifikan dari suasana toko Wellcommshop Mal Citraland terhadap keputusan pembelian konsumen, yang disebabkan baru-bari ini dilakukan perubahan logo Wellcommshop dari warna yang cerah (warna orange) menjadi lebih kalem/soft (warna merah mudah), didalam gerai diputar musik, dan dilakukan penataan produk aksesoris Gadget menarik serta ditata rapih.

\section{Analisis PengaruhVariasi Merchandiseterhadap Keputusan Pembelian aksesoris Gadget}

Uji regresi linier sederhana dilakukan dengan satu variabel dependen dan satu variabel independen, yaitu variasi merchandise terhadap keputusan pembelian. Analisis ini digunakan untuk mengetahui apakah variasi merchandise memberikan pengaruh terhadap keputusan pembelian aksesoris gadget di Wellcommshop Mal Citraland.

Tabel 12 Descriptve Statistics

Descriptive Statistics

\begin{tabular}{|l|r|r|r|}
\hline & \multicolumn{1}{|c|}{ Mean } & Std. Deviation & \multicolumn{1}{|c|}{ N } \\
\hline $\mathrm{Y}$ & 3.5084 & .43964 & 90 \\
$\mathrm{x} 2$ & 3.4213 & .64177 & 90 \\
\hline
\end{tabular}

Sumber : Hasil Pengolahan data, 2010

Analisis Output, yaitu: (1) nilai rata-rata keputusan pembelian3.5084 dengan standard deviasi 0.43964; (2) nilai rata-rata variasi merchandise 3.4213 dengan standard deviasi 0.64177.

Tabel 13 Korelasi antara Variasi Merchandise (X2) terhadap Keputusan Pembelian (Y)

\begin{tabular}{|ll|r|r|}
\hline \multicolumn{4}{|c|}{ Correlations } \\
\hline Pearson Correlation & $\mathrm{y}$ & $\mathrm{y}$ & \multicolumn{1}{c|}{$\mathrm{x} 2$} \\
& $\mathrm{x} 2$ & 1.000 & .768 \\
& $\mathrm{y}$ & .768 & 1.000 \\
\hline Sig. (1-tailed) & $\mathrm{x} 2$ & .000 & .000 \\
& $\mathrm{y}$ & 90 & 90 \\
\hline $\mathrm{N}$ & $\mathrm{x} 2$ & 90 & 90 \\
\hline
\end{tabular}

Sumber: Hasil Pengolahan Data SPSS ver 16.0 
Berdasarkan tabel 4.31 diketahui besar korelasi antara variasi merchandisedengan keputusan pembelian adalah 0.768. Artinya, hubungan kedua variabel tersebut menunjukan tingkat hubungan yang kuat dan searah karena angka tersebut positif. Tingkat signifikan antara variabel variasi merchandise dengan keputusan pembelian sebesar 0.000. Ketentuan menyatakan jika angka probabilitas $<0.05$ maka ada pengaruh yang signifikan antara kedua variabel tersebut.

Tabel 14 Hasil Koefisien Determinasi Variasi Merchandise (X2)

\begin{tabular}{|c|c|c|c|c|}
\hline \multicolumn{5}{|c|}{ Model Summary $^{\mathbf{b}}$} \\
\hline Model & $\mathrm{R}$ & R Square & Adjusted R Square & $\begin{array}{l}\text { Std. Error of the } \\
\text { Estimate }\end{array}$ \\
\hline 1 & $.768^{\mathrm{a}}$ & .590 & .586 & .28295 \\
\hline
\end{tabular}

Sumber : Hasil Pengolahan data, 2010

Nilai koefisien korelasi antara variabel variasi merchandise dengan keputusan pembelian adalah 0.768, menunjukkan hubungan yang positif dan kuat antara variasi merchandise dengan keputusan pembelian. Nilai koefisien determinasi yang digunakan untuk mengetahui besarnya pengaruh variasi merchandise terhadap keputusan pembelianadalah 0.590 atau 59\%. Dengan kata lain besarnya pengaruh variasi merchandise terhadap keputusan pembelian sebesar 59\%, sedangkan sisanya $41 \%$ dipengaruhi oleh variabel lain.

Tabel 15 ANOVA

\begin{tabular}{|c|c|c|c|c|c|c|}
\hline \multicolumn{7}{|c|}{ ANOVA $^{b}$} \\
\hline & & Sum of Squares & $\mathrm{df}$ & Mean Square & $\mathrm{F}$ & Sig. \\
\hline \multirow[t]{3}{*}{1} & Regression & 10.156 & 1 & 10.156 & 126.857 & $.000^{\mathrm{a}}$ \\
\hline & Residual & 7.045 & 88 & .080 & & \\
\hline & Total & 17.202 & 89 & & & \\
\hline
\end{tabular}

Sumber : Hasil Pengolahan data , 2010

Dari uji ANOVA diatas, didapat $\mathrm{F}$ hitung adalah 126.857 dengan tingkat signifikan $0.000<$ 0.05, oleh karena itu H0 ditolak dan H1 diterima. Artinya, ada hubungan linier antara variabel variasi merchandise dengan keputusan pembelian. Oleh karena terdapat hubungan linier antara kedua variabel, maka variasi merchandise memang mempengaruhi keputusan pembelian.

Tabel 16 Koefisien Regresi Sederhana Variasi Merchandise terhadap Keputusan pembelian

\begin{tabular}{|c|c|c|c|c|c|c|}
\hline \multicolumn{7}{|c|}{ Coefficients $^{\mathrm{a}}$} \\
\hline \multirow{2}{*}{\multicolumn{2}{|c|}{ Model }} & \multicolumn{2}{|c|}{ Unstandardized Coefficients } & $\begin{array}{l}\text { Standardized } \\
\text { Coefficients }\end{array}$ & \multirow{2}{*}{$\mathrm{t}$} & \multirow{2}{*}{ Sig. } \\
\hline & & B & Std. Error & Beta & & \\
\hline 1 & (Constant) & 1.708 & .163 & & 10.498 & .000 \\
\hline & $\mathrm{x} 2$ & .526 & .047 & .768 & 11.263 & .000 \\
\hline
\end{tabular}

Sumber: Hasil Pengolahan Data, 2010 
Analisis Output:

Berdasarkan tabel diatas menggambarkan persamaan regresi

$$
\begin{aligned}
& Y=a+b x \\
& Y=1.708+0.526 x
\end{aligned}
$$

Dimana :

$$
\mathrm{Y}=\text { Keputusan Pembelian }
$$

$\mathrm{X}=$ Variasi Merchandise

Simpulan yang didapat yaitu: (1) nilai B constant sebesar 1.708 menyatakan bahwa jika tidak ada kenaikan nilai dari variabel variasi merchandise, maka nilai keputusan pembelian tetap 1.708; (2) Nilai B menyatakan bahwa koefisien regresi variasi merchandise sebesar0.526 artinya setiap peningkatan variasi merchandise akan meningkatkan nilai keputusan pembelian; (3) pada tabel coefficients juga terdapat nilai t hitung. Uji t berguna untuk menguji signifikansi koefisien regresi, yaitu apakah variasi merchandise berpengaruh terhadap keputusan pembelian secara signifikan atau tidak. Ada pengaruh signifikan atas variasi merchandise terhadap keputusan pembelian karena beragamnya aksesoris gadget di Wellcommshop seperti aksesoris handphone, laptop, aksesoris komputer, handycam dan pesaing Wellcommshop di Mal Citraland sendiri hanya menjual satu macam aksesoris yaitu aksesoris handphone.

\section{Analisis Pengaruh Kualitas Pelayanan terhadap keputusan Pembelian aksesoris Gadget}

Uji regresi linier sederhana dilakukan dengan satu variabel dependen dan satu variabel independen, yaitu kualitas pelayanan terhadap keputusan pembelian. Analisis ini digunakan untuk mengetahui apakah kualitas pelayanan memberikan pengaruh terhadap keputusan pembelian aksesoris

\begin{tabular}{|c|c|c|c|}
\hline \multicolumn{4}{|c|}{ Descriptive Statistics } \\
\hline & Mean & Std. Deviation & $\mathrm{N}$ \\
\hline $\mathrm{Y}$ & 3.5084 & .43964 & 90 \\
\hline x3 & 3.4278 & .41822 & 90 \\
\hline
\end{tabular}
gadget di Mal Citraland.

Tabel 17 Descriptve Statistics

Sumber : Hasil Pengolahan data,2010

Analisis Output, yaitu: (1) nilai rata-rata keputusan pembelian 3.5084 dengan standard deviasi 0.43964; (2) nilai rata-rata kualitas pelayanan 3.4278 dengan standard deviasi 0.41822.

Tabel 18 Korelasi antara Kualitas Pelayanan (X3) terhadap Keputusan Pembelian (Y)

Correlations
\begin{tabular}{|lc|r|r|}
\hline \multicolumn{1}{|c|}{} & $\mathrm{y}$ & \multicolumn{1}{c|}{$\mathrm{x} 3$} \\
\hline Pearson Correlation & $\mathrm{Y}$ & 1.000 & .790 \\
& $\mathrm{x} 3$ & .790 & 1.000 \\
\hline Sig. (1-tailed) & $\mathrm{Y}$ &. & .000 \\
& $\mathrm{x} 3$ & .000 & \\
\hline $\mathrm{N}$ & $\mathrm{Y}$ & 90 & 90 \\
& $\mathrm{x} 3$ & 90 & 90 \\
\hline
\end{tabular}

Sumber: Hasil Pengolahan Data SPSS ver 16.0 
Berdasarkan Tabel 18 di atas diketahui besar korelasi antara kualitas pelayanandengan keputusan pembelian sebesar 0.790. Artinya, hubungan kedua variabel tersebut menunjukan tingkat hubungan yang kuat dan searah karena angka tersebut positif. Tingkat signifikan antara variabel kualitas pelayanan dengan keputusan pembelian sebesar 0.000 . Ketentuan menyatakan jika angka probabilitas $<0.05$ maka ada pengaruh yang signifikan antara kedua variabel tersebut.

Tabel 19 Hasil Koefisien Determinasi Kualitas Pelayanan

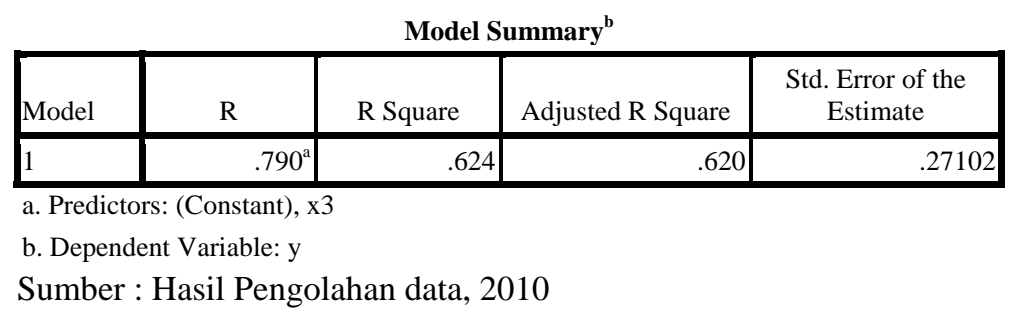

Nilai koefisien korelasi antara variabel kualitas pelayanan dengan keputusan pembelian adalah 0.790, menunjukkan hubungan yang positif dan kuat antara kualitas pelayanan dengan keputusan pembelian. Nilai koefisien determinasi yang digunakan untuk mengetahui besarnya pengaruh kualitas pelayanan terhadap keputusan pembelian adalah 0.624 atau $62.4 \%$. Dengan kata lain besarnya pengaruh kualitas pelayanan terhadap keputusan pembelian sebesar $62.4 \%$, sisanya $37.6 \%$ dipengaruhi variabel lainnya.

Tabel 20 ANOVA

\begin{tabular}{|c|c|c|c|c|c|c|}
\hline \multicolumn{7}{|c|}{ ANOVA $^{b}$} \\
\hline & & Sum of Squares & Df & Mean Square & $\mathrm{F}$ & Sig. \\
\hline \multirow[t]{3}{*}{1} & Regression & 10.738 & 1 & 10.738 & 146.198 & $.000^{\mathrm{a}}$ \\
\hline & Residual & 6.464 & 88 & .073 & & \\
\hline & Total & 17.202 & 89 & & & \\
\hline \multicolumn{7}{|c|}{ a. Predictors: (Constant), x3 } \\
\hline \multicolumn{7}{|c|}{ b. Dependent Variable: y } \\
\hline \multicolumn{7}{|c|}{ Sumber : hasil Pengolahan data , 2010} \\
\hline
\end{tabular}

Dari uji ANOVA di atas, didapat $\mathrm{F}$ hitung adalah 146.198 dengan tingkat signifikan 0,000 < 0.05, oleh karena itu H0 ditolak dan H1 diterima. Artinya, ada hubungan linier antara kualitas pelayanan dengan keputusan pembelian. Oleh karena terdapat hubungan linier antara kedua variabel, maka kualitas pelayanan memang mempengaruhi keputusan pembelian.

Tabel 21 Koefisien Regresi Sederhana Kualitas Pelayanan (X3) terhadap Keputusan Pembelian (Y)

\begin{tabular}{|c|c|c|c|c|c|c|}
\hline \multicolumn{7}{|c|}{ Coefficients $^{\mathrm{a}}$} \\
\hline \multirow{2}{*}{\multicolumn{2}{|c|}{ Model }} & \multicolumn{2}{|c|}{ Unstandardized Coefficients } & $\begin{array}{l}\text { Standardized } \\
\text { Coefficients }\end{array}$ & \multirow[b]{2}{*}{$\mathrm{t}$} & \multirow[b]{2}{*}{ Sig. } \\
\hline & & B & Std. Error & Beta & & \\
\hline \multirow[t]{2}{*}{1} & (Constant) & .661 & .237 & & 2.789 & .006 \\
\hline & x3 & .831 & .069 & .790 & 12.091 & .000 \\
\hline
\end{tabular}


Analisis Output :

Berdasarkan tabel 4.39 diatas menggambarkan persamaan regresi

$$
\begin{aligned}
& \mathrm{Y}=\mathrm{a}+\mathrm{bx} \\
& \mathrm{Y}=0.661+0.831 \mathrm{x}
\end{aligned}
$$

Di mana :

$\mathrm{Y}=$ Keputusan Pembelian

$\mathrm{X}=$ Kualitas Pelayanan

Simpulan yang didapat yaitu: (1) Nilai B constant sebesar 0.661 menyatakan bahwa jika tidak ada kenaikan nilai dari variabel kualitas pelayanan, maka nilai keputusan pembelian tetap 0.661; (2) Nilai B menyatakan bahwa koefisien regresi kualitas pelayanan sebesar 0.831 artinya setiap peningkatan kualitas pelayanan akan meningkatkan nilai keputusan pembelian; dan (3) Pada tabel coefficients juga terdapat nilai t hitung. Uji t berguna untuk menguji signifikansi koefisien regresi, yaitu apakah kualitas pelayanan berpengaruh terhadap keputusan pembelian secara signifikan atau tidak.

Kualitas pelayanan terhadap keputusan pembelian berpengaruh secara signifikan karena SPG/SPB sebelum dipekerjakan di gerai Wellcommshop mereka ditranning terlebih dahulu oleh pihak perusahaan agar dapat bekerja dengan baik seperti menguasai produk-produk Wellcommshop yang luas.

\section{Analisis Pengaruh Suasana toko, Variasi Merchandise dan Kualitas Pelayanan terhadap Keputusan Pembelian aksesoris Gadget}

Uji regresi berganda dilakukan dengan satu variabel dependen dan tiga variabel independen. Pengujian ini dilakukan untuk mengetahui variabel independen, yaitu suasana toko, variasi merchandise dan kualitas pelayanan terhadap variabel dependen, yaitu keputusan pembelian. Pengujian ini dilakukan dengan menggunakan SPSS 16.0 untuk mengetahui variabel-variabel independen yang berpengaruh terhadap variabel dependen. Pengujian ini juga bertujuan untuk mengetahui seberapa besar pengaruh suasana toko, variasi merchandise, dan kualitas pelayanan terhadap keputusan pembelian aksesoris gadget di Mal Citraland.

\begin{tabular}{|c|c|c|c|}
\hline \multicolumn{4}{|c|}{ Descriptive Statistics } \\
\hline & Mean & Std. Deviation & $\mathrm{N}$ \\
\hline $\mathrm{Y}$ & 3.5084 & .43964 & 90 \\
\hline $\mathrm{x} 1$ & 3.5291 & .44279 & 90 \\
\hline$x 2$ & 3.4213 & .64177 & 90 \\
\hline x3 & 3.4278 & .41822 & 90 \\
\hline
\end{tabular}

Tabel 22 Descriptve Statistics

Sumber : Hasil Pengolahan data,2010

Analisis Output, yaitu: (1) Nilai rata-rata keputusan pembelian 3.5084 dengan standard deviasi 0.43964; (2) Nilai rata-rata suasana toko 3.5291 dengan standar deviasi 0.44279; (3) Nilai rata-rata variasi merchandise3.4213 dengan standar deviasi 0.64177; dan (4) Nilai rata-rata kualitas pelayanan 3.4278 dengan standard deviasi 0.41822 . 
Tabel 23 Model Summarry

\begin{tabular}{|l|r|r|r|r|}
\hline \multicolumn{1}{|c|}{ Model Summary $^{\mathbf{b}}$} \\
Model & $\mathrm{R}$ & $\mathrm{R}$ Square & Adjusted R Square & $\begin{array}{c}\text { Std. Error of the } \\
\text { Estimate }\end{array}$ \\
\hline 1 & $.876^{\mathrm{a}}$ & .768 & .760 & .21542 \\
\hline
\end{tabular}

a. Predictors: (Constant), x3, x2, x1

b. Dependent Variable: y

Sumber : Hasil Pengolahan data, 2010

Nilai koefisien korelasi antara variabel suasana toko, variasi merchandise dan kualitas pelayanan dengan keputusan pembelian adalah 0.876, menunjukkan hubungan yang positif dan kuat antara suasana toko, variasi merchandise dan kualitas pelayanan dengan keputusan pembelian. Nilai koefisien determinasi sebesar 0.760 atau $76 \%$, artinya besarnya pengaruh suasana toko, variasi merchandise dan kualitas pelayanan terhadap keputusan pembelian sebesar $76 \%$, sisanya $24 \%$ dipengaruhi oleh variabel lainnya.

Tabel 24 ANOVA

ANOVA $^{\text {b }}$

\begin{tabular}{|ll|r|r|r|r|r|}
\hline Model & & Sum of Squares & df & Mean Square & F & Sig. \\
\hline 1 & Regression & 13.211 & 3 & 4.404 & 94.900 & $.000^{\mathrm{a}}$ \\
& Residual & 3.991 & 86 & .046 & & \\
& Total & 17.202 & 89 & & & \\
\end{tabular}

a. Predictors: (Constant), x3, x2, x1

b. Dependent Variable: $y$

Sumber : hasil Pengolahan data , 2010

Dari uji ANOVA diatas, didapat F hitung adalah 94.900 dengan angka signifikansi 0,000 < 0.05, oleh karena itu Ho ditolak dan H1 diterima. Artinya, ada hubungan linier antar variabel suasana toko, variasi merchandise dan kualitas pelayanan dengan keputusan pembelian. Oleh karena terdapat hubungan linier antara keempat variabel, maka variabel suasana toko, variasi merchandise dan kualitas pelayanan memang mempengaruhi keputusan pembelian.

Tabel 25 AnalisisKoefisien Regresi Berganda

\begin{tabular}{|c|c|c|c|c|c|c|}
\hline \multicolumn{7}{|c|}{ Coefficients $^{\mathrm{a}}$} \\
\hline \multirow{2}{*}{\multicolumn{2}{|c|}{ Model }} & \multicolumn{2}{|c|}{ Unstandardized Coefficients } & $\begin{array}{l}\text { Standardized } \\
\text { Coefficients }\end{array}$ & \multirow[b]{2}{*}{$\mathrm{t}$} & \multirow[b]{2}{*}{ Sig. } \\
\hline & & B & Std. Error & Beta & & \\
\hline \multirow[t]{4}{*}{1} & (Constant) & .515 & .197 & & 2.618 & .010 \\
\hline & $\mathrm{x} 1$ & .062 & .092 & .062 & .666 & .507 \\
\hline & $x 2$ & .305 & .048 & .446 & 6.324 & .000 \\
\hline & x3 & .505 & .090 & .480 & 5.636 & .000 \\
\hline
\end{tabular}

a. Dependent Variable: y

Sumber : Hasil Pengolahan data,2010 
Analisis Output :

Berdasarkan tabel koefisien diatas menggambarkan persamaan regresi

$$
\begin{aligned}
& Y=a+b 1 x 1+b 2 x 2+b 3 \times 3 \\
& Y=0.515+0.062 x 1+0.305 x 2+0.505 x 3
\end{aligned}
$$

Dimana :

$$
\begin{aligned}
& \text { Y }=\text { Keputusan Pembelian } \\
& \text { X1 = Suasana Toko } \\
& \text { X2 = Variasi Merchandise } \\
& \text { X3 = Kualitas Pelayanan }
\end{aligned}
$$

Simpulan yang didapat, yaitu: (1) Nilai B constant sebesar 0.515 menyatakan bahwa jika tidak ada kenaikan nilai dari variabel suasana toko, variasi merchandise dan kualitas pelayanan, maka nilai keputusan pembelian tetap 0.515; (2) Koefisien regresi suasana toko (X1) sebesar 0.062 artinya setiap peningkatan suasana toko akan meningkatkan keputusan pembelian sebesar 6,2\%. Namun koefisien suasana toko tidak mempengaruhi secara signifikan terhadap keputusan pembelian. Hal itu terlihat dari tingkat signifikan suasana toko sebesar 0.507 yang lebih besar dari 0,05; (3) Koefisien regresi variasi merchandise (X2) sebesar 0.305 artinya setiap peningkatan variasi merchandise akan meningkatkan keputusan pembelian sebesar 30.5\%; (4) Koefisien regresi kualitas pelayanan (X3) sebesar 0.505 artinya setiap peningkatan kualitas pelayanan akan meningkatkan keputusan pembelian sebesar $50.5 \%$.

Dari uraian regresi berganda diatas terlihat bahwa variabel kualitas pelayanan memberikan pengaruh yang sangat besar dan paling signifikan terhadap keputusan pembelian dibanding variabel yang lain, yaitu sebesar 50.5\%. Setelah itu variabel variasi merchandise memberikan pengaruh sebesar $30.5 \%$ dan faktor suasana toko tidak memberikan pengaruh yang signifikan terhadap keputusan pembelian. Hal itu terlihat dari tingkat signifikan suasana toko sebesar 0.507 yang lebih besar dari 0.05, dalam regresi berganda suasana toko tidak berpengaruh secra signifikan terhadap keputusan pembelian karena adanya faktor lain. Salah satu faktor lain yang mempengaruhi keputusan pembelian aksesoris gadget di gerai Wellcommshop Mal Citraland antara lain promosi, cuci gudang, diskon. namun demikian bukan berati faktor suasana toko tidak perlu diperhatikan sebagai salah satu penunjang dalam keputusan pembelian. Faktor suasana toko tetap dapat memberikan sumbangsih terhadap keputusan pembelian konsumen. Untuk meningkatkan keputusan pembelian aksesoris gadget di Wellcommshop, perusahaan perlu menitikberatkan pada faktor yang paling berpengaruh dan signifikan yaitu kualitas pelayanan

\section{SIMPULAN}

Berdasarkan pembahasan dan analisis pada bab sebelumnya mengenai pengaruh antara suasana toko, variasi merchandise, dan kualitas pelayanan terhadap keputusan pembelian aksesoris gadget di Wellcommshop Mal Citraland, maka dapat diambil simpulan sebagai berikut: (1) ternyata suasana toko mempengaruhi keputusan pembelian aksesoris gadget di Wellcommshop Mal Citraland. Suasana toko mempunyai pengaruh yang signifikan terhadap keputusan pembelian aksesoris gadget di Wellcommshop Mal Citraland; (2) selain itu, diketahui pula bahwa variasi merchandise mempengaruhi keputusan pembelian aksesoris gadget di Wellcommshop Mal Citraland. Variasi merchandise mempunyai pengaruh yang signifikan terhadap keputusan pembelian aksesoris gadget di Wellcommshop Mal Citraland; (3) sedangkan kualitas pelayanan mempengaruhi keputusan pembelian. Kualitas pelayanan mempunyai pengaruh yang signifikan terhadap keputusan pembelian aksesoris gadget di Wellcommshop Mal Citraland; (4) berdasarkan hasil analisis regresi berganda, secara bersama-sama suasana toko, variasi merchandise, dan kualitas pelayanan berpengaruh terhadap keputusan pembelian. Secara bersama-sama suasana toko, variasi merchandise, dan kualitas pelayanan mempunyai pengaruh yang signifikan terhadap pembelian aksesoris gadget di Wellcommshop Mal Citraland. 


\section{Saran}

Dengan memperhatikan hasil analisis dan pembahasan pada bab sebelumnya, maka saransaran yang dapat diberikan kepada PT Wellcomm Ritelindo Pratama antara lain: PT Ritelindo Pratama dapat meningkatkan suasana toko terutama dalam penempatan produk, ada beberapa barang yang ditempatkan khusus sehingga hal ini para konsumen tidak lebih leluasa dalam memilih barang belanjaannya didalam toko sehingga tidak terciptanya kedekatan dengan suasana didalam toko. Desain toko dibuat sedemikian menarik dan unik agar menarik konsumen datang ke dalam gerai Wellcommshop. Penataan barang dagangan juga perlu diperhatikan penempatan agar konsumen mudah mencari. PT Wellcomm Ritelindo Pratama dapat menambah variasi merchandise dalam hal model aksesoris gadget yang unik atau berbeda dari pesaing yang lain. Karena konsumen wanita khususnya tidak hanya mencari kegunaan dari aksesoris tersebut namun dari segi keunikan juga dicari dan dapat menimbulkan minat beli konsumen akhirnya memutuskan pembelian. Pemilihan merchandise juga perlu diperhatikan agar mengikuti perkembangan jaman. Perlu diperhatikan menentukan jenis serta jumlah barang dagangan yang akan dijual di Wellcommshop agar tidak monoton satu produk. PT Wellcomm Ritelindo Pratama dapat lebih meningkatkan kualitas pelayanan baik dalam pelayanan sebelum penjualan maupun setelah penjualan terjadi. Para SPG/SPB tetap menjaga keramahtamahan terhadap konsumen dan juga calon konsumen. PT Wellcomm Ritelindo Pratama juga perlu memperhatikan faktor-faktor eksternal lain yang dapat mempengaruhi keputusan pembelian misalnya melakukan promosi besar-besaran untuk memperkenalkan produk Wellcommshop lebih luas lagi ke pengguna gadget.

\section{DAFTAR PUSTAKA}

Adiwaluyo, Ign., E. (Februari, 2010). Fokus menggarap aksesoris gadget. Majalah Marketing. Diakses dari: http://www.marketing.co.id/2010/02/13/fokus-menggarap-aksesoris-gadget/

Gilbert, D. (2003). Retail marketing management. Edinburgh Gate, England: Pearson educated.

Kotler, P. (2003). Marketing management. New Jersey: Pearson Education International.

Kotler, P. (2005). Manajemen pemasaran. Jakarta: Indeks.

Ma’ruf, H. (2006). Pemasaran ritel. Jakarta: Gramedia Pustaka Utama.

Simamora, B. (2004). Panduan riset perilaku konsumen. Jakarta: Gramedia Pustaka Utama.

Schiffman, L. G., \& Kanuk, L. L. (2007). Perilaku konsumen. Jakarta: Indeks.

Sopiah, \& Syihabudhin. (2008). Manajemen bisnis ritel. Yogyakarta: Andi.

Sujana, A. (2004). Retail negotiator guidance menyikap rahasia sukses global retail. Jakarta: Gramedia Pustaka Utama.

Tjiptono, F. (2005). Brand management and strategy. Yogyakarta: Andy.

Whidya, C. U. (2006). Manajemen ritel: Strategi dan implementasi ritel modern. Jakarta: Salemba Empat. 